\title{
PROTECTION OF THE BRAIN FROM HYPOXIA: A REVIEW
}

\author{
F.C. PING AND L.C. Jenkins
}

THE ULTIMATE EFFECT of hypoxia is oxygen deficiency at the mitochondrial level. The brain is particularly sensitive to hypoxia and this, taken with the inability of brain tissue to regenerate, makes hypoxia of the brain a major concern for anaesthetists.

Attention has recently been directed to the problem of protection of the brain from hypoxia. Studies using pharmacological methods are of particular interest. Experimental evidence favouring the use of barbiturates has accumulated to such an extent that some workers are now applying these drugs on an empirical basis in clinical situations.

This presentation reviews some aspects of the mechanisms of cerebral hypoxia with special reference to anaesthesia and emphasizes studies which demonstrate protection against hypoxia of the brain in man.

\section{l. Classification and causes of brain HYPOXIA}

The oxygen available to the brain may be derived from the following equation:

Oxygen availability = cerebral blood flow $(\mathrm{CBF}) \times$ oxygen content of arterial blood $=\mathrm{CBF}$ $\times \mathrm{So}_{2} / 100 \times[\mathrm{Hb}] \times 1.39\left(\mathrm{So}_{2}=\right.$ oxygen saturation of haemoglobin [Hb] $\times$ haemoglobin concentration; 1.39 = amount of oxygen in millilitres which is carried by one gram of haemoglabin).

This permits a functional classification of hypoxia. Thus, a reduction in CBF below a critical level will be ischaemic hypoxia: a reduction in $\mathrm{SO}_{2}$ will be hypoxic hypoxia and a reduction in [ $\mathrm{Hb}$ ] will be anaemic hypoxia. Under normal circumstances the cerebral circulation can compensate for moderately severe degrees of anaemia. Therefore, anaemic hypoxia has minimal clinical significance. The more common causes of brain hypoxia are ischaemic or hypoxic in origin.

F.C. Ping, MB., BCh., BAO, and L.C. Jenkins, B.A., M.D., C.M., F.R.C.P.(C), Department of Anaesthesiology, Faculty of Medicine, University of British Columbia at Vancouver General Hospital.

\section{Ischaemic Hypoxia ${ }^{1}$}

From a clinical standpoint, ischaemia may be global or regional and complete or partial.

Global complete ischaemia may be caused by cardiac arrest and massive post-traumatic swelling of the brain. Conditions which reduce CBF will lead to global incomplete ischaemia. These include hypotension and increased intracranial pressure. Regional complete ischaemia may result from cerebrovascular occlusion (thrombosis or embolism) or from interruption of the blood flow (traumatic or surgical). Cerebral vasospasm such as that following a subarachnoid haemorrhage may lead to regional partial ischaemia.

\section{Hypoxic hypoxia}

Conditions which cause a decrease in arterial oxygen tension result in a reduction in oxygen saturation of haemoglobin. These conditions include:

(a) Reduction of inspired oxygen concentration,

(b) Hypoventilation,

(c) Pulmonary diffusion problems,

(d) Pulmonary shunting, and

(e) Ventilation-perfusion abnormalities.

\section{I. Sensitivity of the Brain to Hypoxia}

Many factors contribute to sensitivity of the brain to hypoxia. These include:

\section{High Resting Energy Requirements}

The brain accounts for three per cent of body weight but receives 15 per cent of the cardiac output and utilizes 20 per cent of the oxygen consumed by the body.

\section{No oxygen stores and low energy reserves}

The normal brain does not oxidize substrates other than glucose and it utilizes both anaerobic and aerobic pathways for the complete oxidation of the glucose molecule. When subjected to total ischaemia, the brain derives its energy by anaerobic energy formation and by the breakdown of available high energy compounds. The energy yield from these sources is poor and in 
man these reserves are used up in approximately five minutes.

\section{No capillary recrutiment}

According to Siesjo, et al. ${ }^{1}$, in some tisues (for example, muscle) the number of capillaries per unit volume of tissue can be increased to meet increased demands for blood flow. In brain tissue, however, all capillaries are open even "at rest", so no recruitment is possible.

\section{Some Significant Aspects of Brain METABOLISM AND HYPOXIA}

In the complete oxidation of the glucose molecule, glucose and glycogen are first broken down anaerobically to pyruvate (the glycolytic reaction) and, in the presence of oxygen, the reaction proceeds via acetyl coenzyme A to its completion through the Krebs cycle and the electron transport chain. For the purpose of this discussion, certain points need to be emphasized.

1. The net result of the glycolytic reaction is 2 mol of adenosine triphosphate (ATP) for each mol of glucose metabolized. Complete oxidation yields $30 \mathrm{~mol}$ of ATP.

2. In the absence of oxygen, pyruvate is converted to lactate and A TP and creatine phosphate decrease. At the same time adenosine disphosphate (ADP) increases. These levels are important because they are clinically measurable. They have been used by research workers to indicate the energy state of tissues. ${ }^{2}$ However, others' maintain that the most sensitive indication of tissue hypoxia is reduction of the adenylate cyclic charge, which is given by the formula

Adenylate cyclic charge $=$ $[\mathrm{ATP}]+0.5[\mathrm{ADP}] /[\mathrm{ATP}]+[\mathrm{ADP}]+[\mathrm{AMP}]^{*}$

3. It is not known with certainty how long the brain can tolerate total ischaemia before irreversible autolytic changes begin. The presence of blood in the vessels during ischaemia appears to prevent adequate reflow in the restitution phase, and this "No Reflow" phenomenon may limit recovery. ${ }^{3}$ Recent studies ${ }^{3}$ in rats anaesthetized with nitrous oxide and oxygen and maintained at normocarbia and normothermia $\left(37^{\circ} \mathrm{C}\right)$ indicate that 15 minutes of total ischaemia is compatible with return of adequate mitochondrial function and energy production.

4. Brain tissues appear to be supplied with an excess of oxygen, for it has been demonstrated that even if the venous $\mathrm{PO}_{2}$ falls to below $1.3 \mathrm{kPa}$

*[ $]=$ concentration
$(10 \mathrm{~mm} \mathrm{Hg})$, there is no biochemical evidence of an energy failure. ${ }^{1}$ However, in hypoxaemia, unconsciousness occurs when the $\mathrm{Pa}_{\mathrm{O}_{2}}$ is reduced to about $3.99 \mathrm{kPa}(30 \mathrm{~mm} \mathrm{Hg})$. There is also evidence to show that when neurological function is still grossly abnormal, the energy state returns towards normal. ${ }^{1}$

Functional disturbances observed in the pres. ence of an unaltered energy state are presently unexplained, but may be due to decreased synthesis of neurotransmitters which are oxygendependent.

\section{Protection of the Brain From Hypoxia}

\section{A. Prevention}

One method of protecting the brain is to avoid the factors that are detrimental to cerebral perfu. sion. Adequate perfusion depends on a critical range of cerebral perfusing pressure, which may be derived from the formula:

Cerebral perfusing pressure $=$ mean arterial pressure minus intracranial pressure

$(\mathrm{CPP}=$ MAP - ICP).

When cerebral perfusing pressure falls below $7.98 \mathrm{kPa}(60 \mathrm{~mm} \mathrm{Hg})$, cerebral blood flow decreases, ${ }^{\prime}$ and when cerebral blood flow falls below a critical lower limit, function of the brain is impaired.

\section{What is this critical lower level of cerebral blood flow (CBF)?}

This is a major question and one not easily answered. Figures vary from study to study and also with the conditions under which cerebral blood flow was measured. Data collected during carotid surgery have been well summarized by Boysen, et al. ${ }^{4}$ who conclude that in patients anaesthetized with nitrous oxide and halothane and maintained at normothermia and normocapnia, the critical level is $18 \mathrm{~m} / 100 \mathrm{~g} / \mathrm{min}$, normal CBF being $44 \mathrm{ml} / 100 \mathrm{~g} / \mathrm{min}$. This figure was arrived at by using Xenon-133 to measure regional CBF while using the electroencephalogram to detect slowing of brain waves. During carotid endarterectomy, this level of flow corresponds to a mean value for "stump pressure" of $6.65 \mathrm{kPa}$ $(50 \mathrm{~mm} \mathrm{Hg})$ in the internal carotid artery distil to the clamp. ${ }^{5}$ Neuronal damage may result from a flow at this level for more than 5 to 10 minutes, since Hays, et $a{ }^{6}{ }^{6}$ found that neurological complications occurred after 5 to 10 minutes of arterial clamping when the stump pressure was below $6.65 \mathrm{kPa}(50 \mathrm{~mm} \mathrm{Hg})$. 
Boysen et al. ${ }^{4}$ therefore recommend that for patients having carotid endarterectomy, unless chronic hypertension is present, a "stump pressure" of $7.35 \mathrm{kPa}(55 \mathrm{~mm} \mathrm{Hg})$ or more should be maintained. At "stump pressures" below 6.65 $\mathrm{kPa}(50 \mathrm{~mm} \mathrm{Hg})$ temporary bypass should be used.

Referring to the above formula for cerebral perfusing pressure, it is apparent that the maintenance of an adequate mean arterial pressure is necessary. The control of intracranial pressure is equally important, particularly in patients in whom intracranial pressure is raised. Anaesthesia in this type of patient must be meticulous and special precautions should be taken at induction to avoid further increase in intracranial pressure.

\section{B. Non-pharmacological protection}

\section{Hyperientilation}

Hypocapnia constricts blood vessels and leads to reduced cerebral blood flow. In normal brain the cerebral blood flow changes $2 \mathrm{ml} / 100 \mathrm{~g}$ per $\mathrm{mm} \mathrm{Hg}$ change in $\mathrm{Pa}_{\mathrm{CO}_{2}}$, over a range of $2.66 \mathrm{kPa}$ to $10.66 \mathrm{kPa}$ (20 to $80 \mathrm{~mm} \mathrm{Hg}$ ). ${ }^{7}$ Applying this concept to ischaemic brain tissue, Lassen ${ }^{8,9}$ argued that hypocapnic ventilation would have beneficial effecrs. He postulated that blood vessels around ischaemic areas had lost the capacity to respond to changes in $\mathrm{Pa}_{\mathrm{CO}}$ and would receive blood which was shunted from normally responding blood vessels in healthy areas of the brain the so-called "Robin Hood Syndrome" or "inverse steal syndrome".

Shortly after Lassen's postulate Soloway, et al. ${ }^{10}$ working in canine models of experimentally produced cerebral ischaemia, reported that hypocapnic ventilation resulted in smaller infarctions than with normocapnia. This study appeared to substantiate Lassen's theory and the idea that hyperventilation might play some protective role in ischaemia of the brain appeared promising. However, subsequent animal studies ${ }^{11.12}$ failed to confirm the findings of Soloway, et al. Furthermore, extensive clinical studies using hyperventilation in the treatment of patients with the stroke syndrome failed to demonstrate valuable benefits. ${ }^{13}$

The available data thus indicate that the inverse steal syndrome does not occur in all cases of cerebral ischaemia. In the absence of measurements of cerebral blood flow in the operating room or intensive care unit, maintenance of normal $\mathrm{Pa}_{\mathrm{CO}_{2}}$ or only slight reduction is advocated.

\section{Hypothermia}

At present, hypothermia is the only established method of protection against hypoxia of the brain in man. It has been and is still widely used in cardiac surgery in infants, permitting the "safe" period of circulatory arrest to be extended from approximately four minutes at $37^{\circ} \mathrm{C}$ to at least 35 minutes at $17^{\circ} \mathrm{C} .14$

Hypothermia probably acts by decreasing the rate of oxygen utilization by the brain. Michenfelder and Theye $\mathrm{e}^{2}$ have reported that cooling the brain to $30^{\circ} \mathrm{C}$ significantly decreased the rates of ATP depletion and lactate accumulation in dogs.

In man the rate of oxygen utilization by the brain decreases about seven per cent for each degree centigrade decrease in temperature. ${ }^{15}$

At issue, however, is whether or not hypothermia has a beneficial effect in clinical stroke. The evidence is conflicting. ${ }^{14}$ It was protective in dogs subjected to occlusion of the middle cerebral artery and cooled to $22-24^{\circ} \mathrm{C}$. In another study in monkeys, hypothermia to $29^{\circ} \mathrm{C}$ had a detrimental effect in experimental stroke. ${ }^{16}$ This difference in results is largely unexplained, but reasons proposed include differences due to species and increased blood viscosity induced by hypothermia.

\section{Barbiturate protection}

There is now evidence from experimental animals suggesting that barbiturates have a protective effect in hypoxia of the brain. In animal models of focal and global ischaemia protection has been gauged neurologically by the amount of functional deficit produced, pathologically by the frequency and extent of infarcted lesions and biochemically by the energy state of the tissues. Based on these studies, the following conclusions have been drawn:

1. Barbiturates are protective in experimentally produced (a) regional ischaemia, ${ }^{17.18}$ (b) global ischaemia, ${ }^{14.19}$ (c) cerebral oedema. ${ }^{20}$

2. Protection has not been clearly demonstrated in hypoxic hypoxia. ${ }^{19}$

3. Protection by barbiturates is time-related, being apparent when barbiturates are administered before and within one hour after the lesions were produced ${ }^{21}$

4. Dosages of barbiturates varied from species to species. Most studies of focal ischaemia have used the middle cerebral artery occlusion model. Smith, et al. ${ }^{17}$ subjected dogs to unilateral ligations of the internal carotid and the middle cerebral arteries during each of the following anaesthetic regimens: 
(a) light halothane $(0.8$ per cent end tidal);

(b) deep halothane ( 1.9 per cent end tidal);

(c) deep halothane with mean arterial pressure reduced to $55 \mathrm{~mm} \mathrm{Hg}$;

(d) pentobarbitone $(56 \mathrm{mg} / \mathrm{kg})$;

(e) light halothane plus thiopentone $40 \mathrm{mg} / \mathrm{kg}$ immediately before occlusion of the cerebral artery; and

(f) light halothane plus thiopentone $40 \mathrm{mg} / \mathrm{kg}$ begun 15 minutes after occlusion.

The animals were anaesthetized for six hours, during which time variables likely to affect cerebral haemodynamics were controlled (body temperature, $\mathrm{pH}, \mathrm{Pa}_{\mathrm{CO}_{2}}, \mathrm{~Pa}_{\mathrm{O}_{2}}$ and arterial blood pressure). Neurological examinations were performed daily. On the seventh day, the dogs were sacrificed.

These workers found that with the exception of the group receiving barbiturates, most of the dogs suffered some degree of hemiplegia. Only one of the "barbiturate" dogs had a transient unilateral weakness. When their brains were examined infarctions of similar size were found in both the "awake" control group and the light halothane group (approximately 10 per cent of the affected hemisphere). Deep halothane anaesthesia increased infarction size three-fold when compared to the "awake" group. In contrast, in the group anaesthetized with barbiturates, the highest mean infarction size was 2.7 per cent of the affected hemisphere.

To overcome criticism that an inappropriate animal model was used, studies of experimental focal ischaemia were undertaken in primates, since occlusion of the middle cerebral artery (MCA) in primates produced an ischaemic lesion resembling that in man. ${ }^{22}$ Thus Moseley, et al. ${ }^{23}$ reported that Rhesus monkeys, treated with a pentobarbitone infusion for 12 hours following segmental occlusion of the middle cerebral artery had less neurological deficit and smaller infarctions compared to non-barbiturate control animals, which had more severe symptoms and larger lesions. In baboons, Hoff, et $a l^{18}$ also reported the protective effects of barbiturates following middle cerebral artery occlusion.

In an effort to simulate the clinical stroke syndrome of man, Michenfelder, et at.,${ }^{22}$ produced acute stroke in 18 Java monkeys by permanently occluding the middle cerebral artery and followed this with $\mathbf{4 8}$ hours of intensive care. In nine monkeys pentobarbitone was administered $30 \mathrm{~min}$ utes after occlusion $(14 \mathrm{mg} / \mathrm{kg}$ initially and 7 $\mathrm{mg} / \mathrm{kg}$ intravenously every (wo hours) for 42 hours. The other nine monkeys were controls.
Factors affecting cerebral haemodynamics were controlled. The study lasted seven days. All monkeys in the pentobarbitone group survived the seven days whereas three of the control monkeys died within the first 48 hours. In the pentobarbitone group five of nine monkeys had no apparent neurological deficit at any time. In the control group, eight of the nine monkeys showed impairment of neurological function. At autopsy on the seventh day the size of the infarct correlated with the magnitude of the deficit.

Biochemical data suggesting brain protection from barbiturates came from Michenfelder and Theye. ${ }^{19}$ Five dogs were treated with thiopentone $15 \mathrm{mg} / \mathrm{kg}$ intravenously over a 60 -second period. Then global ischaemia was rapidly induced to a mean arterial pressure of $3.3 \mathrm{kPa}$ $(25-30 \mathrm{~mm} \mathrm{Hg}) . \mathrm{Pa}_{\mathrm{O}_{2}}$ was held at $7.3 \mathrm{kPa}(130 \mathrm{~mm}$ $\mathrm{Hg}$ ) and maintained for nine minutes. During this period, brain biopsies were obtained at intervals from exposed cerebral hemispheres and rapidly frozen in liquid nitrogen. The cerebral specimens were then assayed for ATP and lactate concentrations and the results were compared with a non-barbiturate control group. Significantly higher energy levels were observed at the 1.5-and 5-minute intervals in the thiopentone-treated group. At nine minutes A TP concentrations were similar in brain biopsies from both groups.

In a remarkable study by Nemoto (see Smith ${ }^{14}$ ), monkeys were subjected to complete global ischaemia for 16 minutes and then received seven days of intensive care treatment. One group of monkeys which received thiopentone 90 $\mathrm{mg} / \mathrm{kg}$ five minutes after ischaemia recovered completely, while control monkeys were unable to feed, sit or walk and responded poorly to painful stimuli.

The evidence for protection in cerebral oedema comes from a recent study done by Smith and Marque $^{20}$ in dogs. In experimentally produced cerebral oedema, these workers reported that pentobarbitone anaesthesia $(60 \mathrm{mg} / \mathrm{kg}) \mathrm{lim}-$ ited the extent of cerebral oedema, whereas inhaled anaesthetics did not. The oedema produced was of a type that occurred naturally around cerebal tumors, infarctions and in head injury.

Based on these studies, barbiturates are now being used clinically in man. Treatment of deeply comatose patients with barbiturates in an intensive care selting had favourable result $\mathrm{s}^{24}$ and Wade ${ }^{25}$ is now using thiopentone in a dose of 4-5 $\mathrm{mg} / \mathrm{kg}$ before carotid occlusion in operations on the carotid artery. The doses chosen are empiri- 
cal. Whether or not protection is provided against hypoxia of the brain in man remains to be established.

\section{Mechanism of Barbiturate Protection}

The mechanism by which barbiturates exert their protective action is obscure. A variety of views are held. Barbiturates are capable of reducing the rate of oxygen utilization by the brain by as much as 50 per cent and may provide cerebral protection by reducing cerebral function. ${ }^{19}$ Smith, et al. ${ }^{17}$ believe that barbiturates protect principally by decreasing cerebral blood flow and intracranial pressure. The decreased cerebral blood flow would reduce cerebral oedema and thus allow for better perfusion to ischaemic areas. Siesjo ${ }^{26}$ has postulated that free radicals are produced during tissue hypoxia and that these cause cell damage. Since barbiturates are efficient free radical scavengers, this is the mechanism of their action.

\section{SUMMARY}

A functional classification of hypoxia of the brain has been presented and some of its significant aspects have been discussed. Mechanisms of protection from hypoxia of the brain were reviewed under the headings of prevention, hyperventilation, hypothermia and protection by barbiturates.

In prevention of hypoxia of the brain, avoidance of factors producing a fall in cerebral perfusing pressure was emphasized. Hyperventilation is not advised unless one can readily measure regional cerebral blood flow. In the operating room, normocarbia or slight hypocarbia is recommended.

Animal studies indicale a protective role of barbiturates in ischaemic hypoxia of the brain. However, it should be emphasized that, at present, hypothermia is the only established means of protection against hypoxia of the brain in man, when it is induced prior to the hypoxic insult. The evidence for protection by barbiturates has been found only in experimental animals. If one can extrapolate the results of studies in animals to man, then potential benefits would be expected in clinical stroke, cardiac arrest, in operations on the carotid artery and in head injury.

\section{RÉsumÉ}

Les auteurs présentent une classification fonctionnelle de l'hypoxie cérébrale el en discutent certains aspects importants. Les mécanismes de protection du cerveau contre l'hypoxie sont étudiés en relation avec la prévention, l'hyperventilation, l'hypothermie et les effets des barbituriques.

Dans la prévention de l'hypoxie cérébrale, il est important d'èviter une baisse de la pression de perfusion. L'hyperventilation est à déconseiller à moins que la mesure du débit sanguin régional ne soit disponible. En salle d'opération, on recommande la normocapnie ou une légère hypocapnie.

Des études sur les animatux ont montré le rôle protecteur joué par les barbituriques dans l'ischémie hypoxique. Cependant, il faut insister sur le fait que, jusqu'à maintenant, l'hypothermie, lorsqu'elle précède l'agression hypoxique. est le moyen reconnu de protection pour le cerveau. L'effet bénéfique des barbituriques n'a été démontré que chez l'animal de laboratoire. Si on applique ces résultats à l'humain, on peut s'attendre à ce que le traitement aux barbituriques soit utile dans l'accident cérébro-vasculaire, I'arrèt cardiaque, la chirurgie de la carotide et le traumatisme crânien.

\section{REFERENCES}

I. Siesuo, B.K., Norberg, K., Lunnggren, B., \& SALFORD, L.G. Hypoxia and cerebral metabolism - a basis and practice of neuroanaesthesia. Excerpra Medica. Ed. Emeric Gordon. pp. 47-82 (1975).

2. Michenfelder, J.D. \& Theye, R.A. The effects of anaesthe sia and hypothermia on canine cerebral ATP and lactate during anoxia produced by decapitation. Anaesthesiology 33: 430 (1970).

3. Lunnggren, B., Ratcheson, R.A., \& Siesio, B.K. Cerebral metabolic state following complete compression ischemia. Brain Research 73: 29! (1974).

4. Boysen, G., Engell, H.C., Pistolese, G.R. Fioraui, P., Agnoh, A., \& Lassen, N.A. Critical lower level of cerebral blood flow in man with particular reference to carotid surgery. Editorial: Circulation 49: 1023 (1974)

5. LASSEN, N. Anaesthesia and cerebral flood fiow. A.S. A. Refresher Course Lectures (1975).

6. HAYS, R.J., LeVinson, S.A., \& WYLIE, E.J Intra-operative measurement of carotid back pressure as a guide to operative management for carotid endarterectomy. Surgery 72: 953 (1972).

7. Shapiro, H.M. Physiologic and pharmacologic regulation of cerebral blood flow. ASA Refresher Course Lectures (1976).

8. LASSEN, N.A. Luxury perfusion syndrome and its possible relation to acute metabolic acidosis localized within the brain. Lancet 2: 1113-1115 (1966).

9. Lassen, N.A. \& Palvalgyi, R. Cerebral steal during hypercapnia and the inverse reaction during 
hypocapnix observed by the 133 xenon technique in man. Scand, J. Lab. Clin. Invest. Suppl. 102: XIIID (1968).

10. Soloway, M., Nadel, W., \& Albin, M.S. The effect of hyperventilation on subsequent cerebral infarction. Anesthe siology 29: 975 (1968).

11. Soloway, M. Moriarty, G., \& Fraser, J.G. Effect of delayed hyperventilation on experimental cerebral infarction. Neurology $21: 479$ (1971).

12. Yamaguchi, T., Regh, F., \& Waltz, A.G. Effects of hyperventilation with and without carbon dioxide on experimental cerebral ischemia and infarction. Brain 95: 123 (1972).

13. Chaistensen, M.A., Paulson, O.B., Olesen, J., Alexander, S.G., Skinhos, E., DaM. W.H., \& LASSEN, N.A. Cerebral apoplexy (stroke) treated with or without prolonged artificial ventilation. 1. Cerebral circulation, clinical course and cause of death. Stroke 4: 568 (1973).

14. SMITH, A.L. Barbiturate protection in cerebral hypoxia. Anaesthesiology 47: 285 (1977).

15. SMITH, A.L. \& WollmaN, H. Cerebral blood flow and metabolism. Effects of anesthetic drugs and techniques. Anesthesiology 36: 378 (1972).

16. MichenfeldeE, J.D. Failure of prolonged hypocapnia, hypothermia or hypertension to favourably alter acute stroke in primates. Stroke $8:$ (1977).

17. Smith, A. L., Hoff, T.T., Nielsen, S.L., \& Larson, C.P. Barbiturate protection in acute focal cerebral ischemia. Stroke 5: 1 (1974).
18. Hoff, J.T., SMith, A.L., Hankinson, H.L., \& NiELSEN, S.L. Barbiturate protection from cerebral infarction in primates. Stroke 6: 28 (1975).

19. Michenfelder, J.D. \& Theye, R.A. Celebral protection by thiopental during hypoxia. Anesthesiology 39: 510 (1973).

20. SMITH, A.L. \& Marque, J. Anesthetics and cerebral edema. Anesthesiology 45: 64 (1976).

21. Gorkill, G., Chikoval, O.I.L., \& Mcleish, 1. Timing of pentobarbital administration for brain protection in experimental stroke. Surgical Neurology 5: 147 (1976).

22. Michenfelder, J.D., MILde, J.H., \& SUNdT, T.M. Cerebral protection by barbiturate anaesthesia. Archives of Neurology 33: 345 (1976)

23. Moseley, J., Laurent, J.P., \& Mol.inari, G.F. Barbiturate attenuation of the clinical course and pathological lesions in a primate stroke model. Neurology 25: 870 (1975).

24. Marshall, L.F. \& Shapiro, H.M. Barbituate control of intracranial hypertension in head injury. ASA Scientific Abstracts, p. 83 (1977).

25. WADE, J.G. Carotid endarterectomy: the anaesthetic challenge. ASA Refresher Course Lectures (1977).

26. Siesso, B.K. Effect of anaesthesia and hypoxia on cerebral metabolism. ASA Refresher Course Lectures (1976). 